\title{
Rapamycin and fructose-1,6-bisphosphate reduce the HEPG2 cell proliferation via increase of free radicals and apoptosis
}

\author{
ELISA FELLER GONÇALVES DA SILVA ${ }^{1,2}$, GABRIELE CATYANA KRAUSE ${ }^{1}$, \\ KELLY GOULART LIMA ${ }^{1}$, GABRIELA VIEGAS HAUTE ${ }^{1}$, LEONARDO PEDRAZZA ${ }^{1}$, \\ FERNANDA CRISTINA MESQUITA ${ }^{1}$, BRUNO SOUZA BASSO ${ }^{1}$, ANDERSON CATARINA VELASQUEZ ${ }^{1}$, \\ FERNANDA BORDIGNON NUNES ${ }^{1,3}$ and JARBAS RODRIGUES DE OLIVEIRA ${ }^{1,2}$
}

\begin{abstract}
${ }^{1}$ Laboratory of Cellular Biophysics and Inflammation, Department of Cellular and Molecular Biology, School of Biosciences, Pontifícia Universidade Católica do Rio Grande do Sul (PUCRS), Porto Alegre, Rio Grande do Sul, CEP 90619-900; ${ }^{2}$ Professional Masters in Pharmaceutical Biotechnology, Pharmacy School, Pontifícia Universidade Católica do Rio Grande do Sul (PUCRS), Porto Alegre, Rio Grande do Sul, CEP 90619-900; ${ }^{3}$ Clinical Medicine from Universidade Federal do Rio Grande do Sul (UFCSPA), Porto Alegre, Rio Grande do Sul, CEP 90050-170, Brazil
\end{abstract}

Received March, 5, 2016; Accepted June 21, 2016

DOI: 10.3892/or.2016.5111

\begin{abstract}
Hepatocellular carcinoma is the most prevalent type of tumor among primary tumors affecting the liver. Rapamycin is currently used as a basis for chemotherapy in the treatment of cancers, including the liver. Because it shows several adverse effects, minimizing these effects without compromising efficacy is important. In this sense other drugs may be used concomitantly. One of these drugs is fructose1,6-bisphosphate (FBP), which has shown therapeutic effect in various pathological situations, having antioxidant and anti-inflammatory proprieties. The objective of the present study was to evaluate the activity of rapamycin in combination with the FBP in HepG2 cell proliferation and the mechanisms involved. HepG2 cells were analyzed after $72 \mathrm{~h}$ of treatment with both drugs. Cell proliferation, cytotoxicity, cytokines, apoptosis, senescence, autophagy and oxidative stress were accessed. It was demonstrated that the combination is more efficient than the single use of substances, because subtherapeutic doses of rapamycin, when associated to FBP become effective, reducing cell proliferation, through a significant increase in the production of tiobarbituric acid reactive substances (TBARS), suggesting that this might be the cause of death by apoptosis. According to these results, we believe that the association of both drugs may be a promising choice for the treatment of hepatocarcinoma.
\end{abstract}

Correspondence to: Dr Elisa Feller Gonçalves da Silva, Laboratory of Cellular Biophysics and Inflammation, Department of Cellular and Molecular Biology, Pontifícia Universidade Católica do Rio Grande do Sul (PUCRS), Avenida Ipiranga 6681, prédio 12, bloco C, sala 221, Porto Alegre, Rio Grande do Sul, CEP 90050-170, Brazil

E-mail: elisa.feller@acad.pucrs.br

Key words: rapamycin, fructose-1,6-bisphosphate, HepG2 cells, hepatocellular carcinoma, free radicals, apoptosis

\section{Introduction}

Hepatocellular carcinoma (HCC) is among the leading diseases in the world today, being the fifth most common malignant tumor, representing $85 \%$ of primary liver tumors and accounting for nearly two thirds of death among cancers. The prognosis is generally poor due to rapid tumor growth and the absence of symptoms at the beginning of the disease $(1,2)$.

The chronic inflammatory state appears to be necessary for the initiation and development of liver cancer and the HCC is an example of inflammation-related cancer $(3,4)$. The presence of underlying diseases, such as hepatitis $\mathrm{B}$ and $\mathrm{C}$, is a major cause of tumor (5). HCC is among the top ten cancers that affect the world population. Its incidence has increased in recent years, mainly due to infection by the hepatitis $\mathrm{C}$ virus (6).

Among the various types of cancer therapies, surgical resection, radiotherapy and chemotherapy are employed, the latter being the most widely used method. Therapies may be used singly or in combination (3). Even with different options, treatment against cancer is difficult to be handled, mainly due to the low specificity of some drugs and the narrow therapeutic window, which are closely related to toxicity. Thus, the search and development of new therapies is extremely necessary (7). A recent innovation in anticancer therapy is the inhibition of mTOR (mammalian target of rapamycin), which has been shown to suppress the growth of liver tumors and metastasis $(8,9)$. These results are encouraging, but the HCC often shows higher resistance to rapamycin when used alone. Therefore, new studies have investigated the association of rapamycin with other antitumor drugs to reduce or avoid treatment resistance $(10,11)$.

Rapamycin, a macrocyclic lactone produced by Streptomyces hygroscopicus, molecular formula C51 H79 NO13 and molecular weight 914.2 , is a highly effective chemotherapy, its mechanism of action is the inhibition 
of mTORC1. Since its approval by the US Food and Drug Administration in 1999, rapamycin has been administered to patients who received kidney transplant due to its immunosuppressive activity. In the $80 \mathrm{~s}$, scientists also found that the drug inhibits the growth of tumors and, since 2007, two of its derivatives, temsirolimus (Wyeth) and everolimus (Novartis) have been approved against various cancers, including liver cancer, administered alone or in combination with other drugs $(12,13)$.

The mechanism of action of rapamycin occurs intracellularly where these inhibitors form a complex with the protein bound to FK506 12 (FKBP-12) that is recognized by mTOR. The formation of the complex results in the inhibition of the activity of mTOR, and the S6K expression of the protein will result in the inhibition of cell cycle progression, survival and angiogenesis $(14,15)$.

Clinical and experimental evidence shows strong correlation between the dosage and the toxicity. Rapamycin induces side-effects such as nausea, vomiting, anemia, hyperlipidemia, respiratory, cardiovascular, and nephrotoxicity, which are dose-dependent and limit the administration of higher dosages, thus, compromising therapeutic efficacy. Nephrotoxicity is one of the major limitations and, for this reason, the monitoring of the renal function is required during treatment $(16,17)$. This makes inadequate doses the most significant obstacle in the exact definition of the clinical role of rapamycin, and probably in expanding its activity. Therefore, when high doses are administered, rapamycin is essential to identify the effective drug carrier that can prevent or counteract the side-effects of rapamycin (16). One of them is fructose1,6-bisphosphate (FBP), a sugar which has mechanisms that promote renal protection (18).

Previous studies reported the antioxidant and anti-inflammatory therapeutic properties plus a nephroprotecting effect in animal models of FBP. Knowing that the process of carcinogenesis involves inflammatory mediators such as cytokines, chemokines, and reactive oxygen species, we believe that the FBP can be helpful in maintaining the therapeutic effect of rapamycin and inhibition of adverse effects. Therefore, the aim of the present study was to evaluate the effect of rapamycin alone and in combination with fructose-1,6-bisphosphate on cell death and proliferation, inflammation and oxidative stress parameters in liver carcinoma cells (HepG2). The objective of this study was to evaluate the activity of rapamycin in combination with the FBP in HepG2 cell proliferation and mechanisms involved, looking to determine whether rapamycin ineffective doses can decrease cell proliferation and toxicity, when associated with FBP.

\section{Materials and methods}

Cell culture. Human hepatocarcinoma cell line (HepG2) was obtained from the American Type Culture Collection (ATCC; Manassas, VA, USA). The medium used for the culture of cells was Dulbecco's modified Eagle's medium (DMEM) supplemented with fetal bovine serum (FBS 10\%) under a humidified atmosphere containing $5 \% \mathrm{CO}_{2}$. HepG2 cells, after being cultured and presenting $\sim 70 \%$ confluence, were detached from culture bottles and transferred to 96 -well culture plates at a uniform cell density.
Treatment with rapamycin and fructose-1,6-bisphosphate. The plates were incubated at $37^{\circ} \mathrm{C}$ in a humidified incubator with $5 \% \mathrm{CO}_{2}$ for $72 \mathrm{~h}$, with the objective to establish a doseresponse curve using rapamycin (Wyeth Pharmaceuticals Co., Collegeville, PA, USA), tested in different concentrations of $10,20,30,40$ and $50 \mathrm{nM}(19,20)$ and fructose 1,6 bisphosphate (Sigma-Aldrich, St. Louis, MO, USA) at doses of 5 and $10 \mathrm{mM}$, and in DMEM medium in order to establish dose correlation of cell growth and proliferation. The choice of 72-h treatment time was based on other studies by our laboratory, that have shown that the best growth evaluation time is $72 \mathrm{~h}$, and that at this time the cell growth is $\sim 100 \%$, in other words, the control group doubles the number of cells, which is taken as the ideal internationally to measure proliferation. The FBP concentrations were in agreement with experiments performed in our laboratory on HepG2 cells as was rapamycin on impact articles.

Evaluation of cellular proliferation. The assessment of the viability and cellular growth/proliferation was performed by cell counting in a Neubauer chamber. The experiments were performed in triplicate and repeated three times. After this evaluation the rapamycin doses of 10 and 10 mM FBP were selected.

Measurement of lactate dehydrogenase ( $L D H)$. The test LDH (lactate dehydrogenase) is a marker of membrane integrity. The enzyme lactate dehydrogenase is present throughout the cell cytoplasm, and when the membrane is damaged it is released to the external environment. The LDH allows the analyzes of the number of total inviable (dead) cells (21).

Cytotoxicity was assessed by the presence of the enzyme LDH measured in both supernatants and cell lysate of treatments in HepG2 cells, using the UV kinetic method (Lactate-Pyruvate) by Labtest Diagnostic Kit SA. For the control of cell lysis, a 5\% Tween was used.

Quantification of cytokines. To measure cytokine production we used the BD Cytometric Bead Array (CBA), Human Inflammatory Cytokine CBA kit. According to kit manual, the BD CBA system uses the sensitivity of amplified fluorescence detection by flow cytometry to measure soluble analytes in a particle-based immunoassay. Each bead in a BD CBA kit provides a capture surface for a specific protein and is analogous to an individually coated well in an ELISA plate. The BD CBA capture bead mixture is in suspension to allow for the detection of multiple analytes in a small volume sample (22). The treated HepG2 cells were incubated for $72 \mathrm{~h}$, supernatants were collected and stored at $-20^{\circ} \mathrm{C}$ for later analysis.

Evaluation of apoptosis, senescence and autophagy. HepG2 cells were treated in 24-well plates for a preview of apoptosis, senescence and autophagy. Apoptosis and senescence were evaluated by DAPI (4',6-diamidino-2-phenylindole), a fluorescent staining that binds strongly to regions rich in adenine and thymine in DNA sequences (23). The evaluation of autophagy was by acridine orange (AO), a vital acidotropic fluorescent dye (24). The results were visualized by fluorescent microscope and the apoptotic and senescent nuclei were quantified using Image-Pro Plus software. 


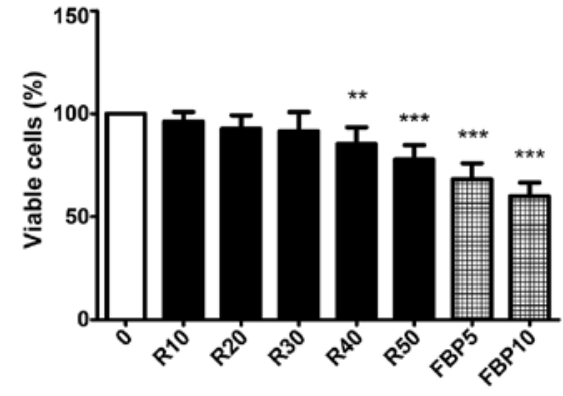

Figure 1. The isolated effect of rapamycin (R) and fructose-1,6-bisphosphate (FBP) on HepG2 cell proliferation. Cells were treated with R $(10-50 \mathrm{nM})$ and FBP (5 and $10 \mathrm{mM}$ ) for $72 \mathrm{~h}$ and cell viability assessed by direct cell count $\mathrm{R} 40 \mathrm{nM}$ reduces proliferation in $15 \%$, R $50 \mathrm{nM}$ in $23 \%$, FBP $5 \mathrm{mM}$ in $32 \%$, and FBP $10 \mathrm{mM}$ in $40 \%$. Data represent the mean \pm SD. Results are expressed in percentage $\left({ }^{* *} \mathrm{P}<0.05\right.$ and ${ }^{* * *} \mathrm{P}<0.001$ vs. control).

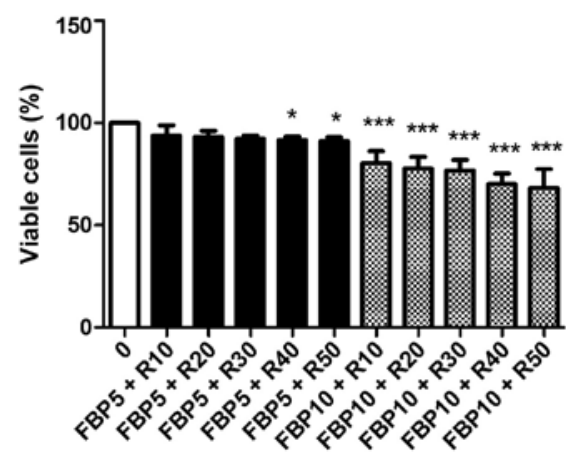

Figure 2. The association effect of rapamycin (R) and fructose-1,6-bisphosphate (FBP) on HepG2 cells proliferation. Cells were treated with the combination of R (10-50 $\mathrm{nM})$ and FBP $(5$ and $10 \mathrm{mM})$ for $72 \mathrm{~h}$ and cell viability assessed by direct cell count. FBP5+R40 and FBP5+R50 reduced proliferation in $9 \%$, FBP10+R 10 in $20 \%, \mathrm{FBP} 10+\mathrm{R} 20$ in $22 \%$, FBP10+R 30 in $23 \%, \mathrm{FBP} 10+\mathrm{R} 4030 \%$ and FBP10+R50 32\%. Data represent the mean \pm SD. Results are expressed in percentage ( ${ }^{*} \mathrm{P}<0.05$ and ${ }^{* * *} \mathrm{P}<0.001$ vs. control).

Evaluation of oxidative stress. Oxidative stress of liver carcinoma cells was measured by the method of thiobarbituric acid (TBARS) by fluorimetry.

Statistical analysis. The results are presented using descriptive statistics (average and standard deviation). For the comparison of average between group analysis of variance (ANOVA) and post hoc Tukey's test for multiple comparisons were used. In the presence of asymmetry the corresponding non-parametric was used. The level of significance was set at $\mathrm{P}<0.05$ with a 95\% confidence interval and the data were analyzed by SPSS software (Statistical Package for Social Sciences) for Windows, version 15.0. (SPSS, Inc., Cincinnati, OH, USA).

\section{Results}

The evaluation of cell proliferation of rapamycin $(\mathrm{R})$ at concentrations of 10, 20, 30, 40 and $50 \mathrm{nM}$, FBP 5 and $10 \mathrm{mM}$ and the association of the two substances was performed. Fig. 1, presents that rapamycin (R) causes a significant decrease in concentrations of 40 and $50 \mathrm{nM}$ and the FBP causes a reduction of cell growth at concentrations of 5 and $10 \mathrm{mM}$. In Fig. 2, it is evident that the association with FBP

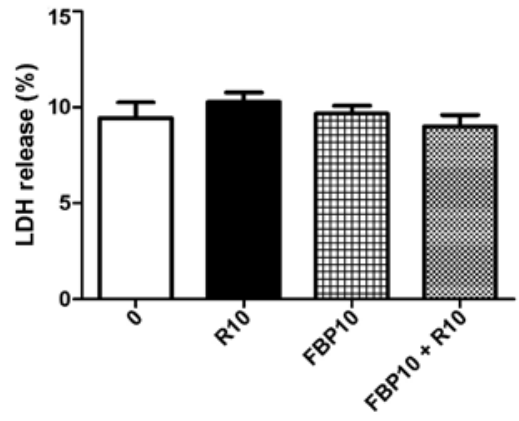

Figure 3. Percent of release of lactate dehydrogenase of HepG2 cells after treatment with rapamycin (R) $10 \mathrm{nM}$, fructose-1,6-bisphosphate (FBP) $10 \mathrm{mM}$ and rapamycin $(\mathrm{R})+$ fructose-1,6-bisphosphate $(\mathrm{FBP}) 10 \mathrm{mM}$. Results are expressed as the mean $\pm \mathrm{SD}$. Results are expressed in percentage.
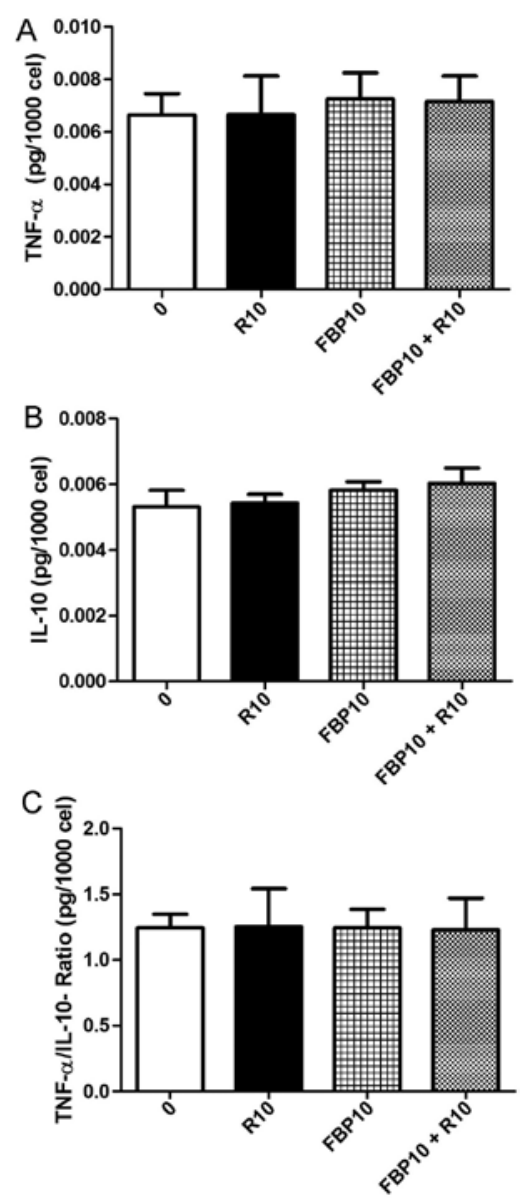

Figure 4. Flow cytometric analyses of TNFa (A), IL-10 (B) and $\mathrm{TNF} \alpha / \mathrm{IL}-10$ ratio (C) in cell supernatant of HepG2 cells after $72 \mathrm{~h}$ of treatment with rapamycin (R) $10 \mathrm{nM}$, fructose-1,6-bisphosphate (FBP) $10 \mathrm{mM}$ and rapamycin (R) + fructose-1,6-bisphosphate (FBP) $10 \mathrm{mM}$. Data represent the mean \pm SD. Cytokine levels are expressed as picograms per 1000 cells.

$10 \mathrm{mM}$ makes the subtherapeutic doses of 10,20 and $30 \mathrm{nM}$ of rapamycin (R) effective. Already in combination with $5 \mathrm{nM}$ of FBP, rapamycin (R) did not decrease cell proliferation in any of the concentrations. For this reason, the doses of $10 \mathrm{mM}$ FBP and $10 \mathrm{nM}$ rapamycin (R) were selected for the following experiments.

The integrity of the membrane of HepG2 cells treated with rapamycin (R) and FBP, isolated and in combination, 

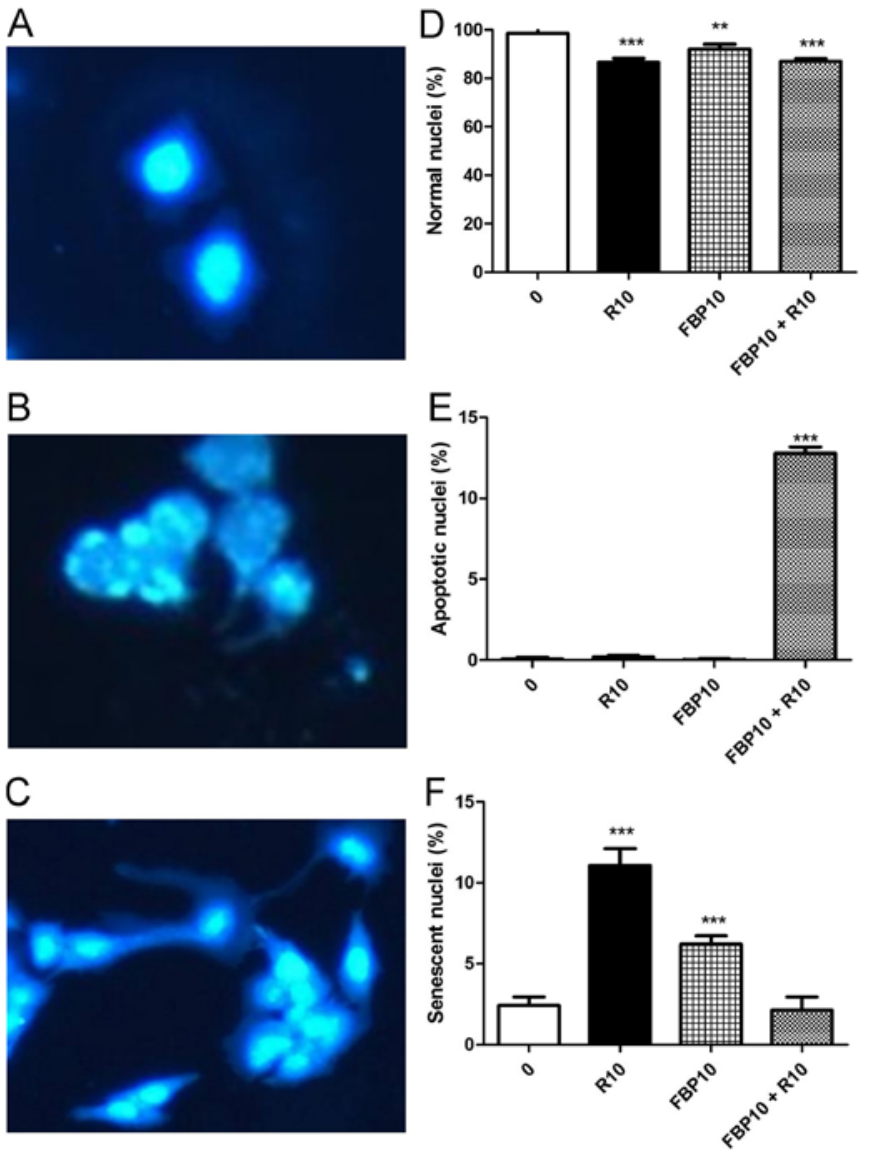

Figure 5. Effects of rapamycin (R) $10 \mathrm{nM}$, fructose-1,6-bisphosphate (FBP) $10 \mathrm{mM}$ and rapamycin $(\mathrm{R})+$ fructose-1,6-bisphosphate (FBP) $10 \mathrm{mM}$ in HepG2 cell nuclei were visualized through images obtained by fluorescent inverted microscope. (A) Normal nuclei, (B) apoptotic nuclei and (C) senescent nuclei. (D) Percent of normal nuclei. Results are expressed as the mean \pm SD. Results were expressed as cell number $\left({ }^{* *} \mathrm{P}<0.05,{ }^{* * *} \mathrm{P}<0.001\right.$ vs. control). (E) Percent of apoptotic nuclei. Results are expressed as the mean \pm SD. Results were expressed as cell number $\left({ }^{* * *} \mathrm{P}<0.001\right.$ vs. control) (F) Percent of senescent nuclei. Results are expressed as the mean \pm SD Results are expressed as the cell number $\left({ }^{* * * *} \mathrm{P}<0.001\right.$ vs. control).

was evaluated through the measurement of LDH in the cell culture supernatant. There was no significant decrease in the percentage of LDH released in any of the groups analyzed, demonstrating that there is no significant increase in cell death associated with necrosis in the treated groups in comparison to the control group (Fig. 3).

Inflammation and cancer are associated, for this reason we evaluated the pro-inflammatory and anti-inflammatory cytokines. We selected tumor necrosis factor $\alpha$, TNF- $\alpha$ (Fig. 4A) and interleukin 10, IL-10 (Fig. 4B). The ratio between the cytokines was also calculated (Fig. 4C). Changes of cytokines in relation to the control were not observed and the ratio gave the balance between pro- and anti-inflammatory cytokines.

To check whether the decrease of cellular proliferation was by apoptosis or senescence, DAPI staining was used. The Fig. 5A presents a picture of normal nuclei, Fig. 5B apoptotic nuclei and Fig. 5C senescent nuclei. In the analysis of normal nuclei, $\mathrm{R}$ and FBP, isolated and in combination, had a significant decrease (Fig. 5D). Associated with that result, we had a significant increase of apoptotic nuclei percentage in the
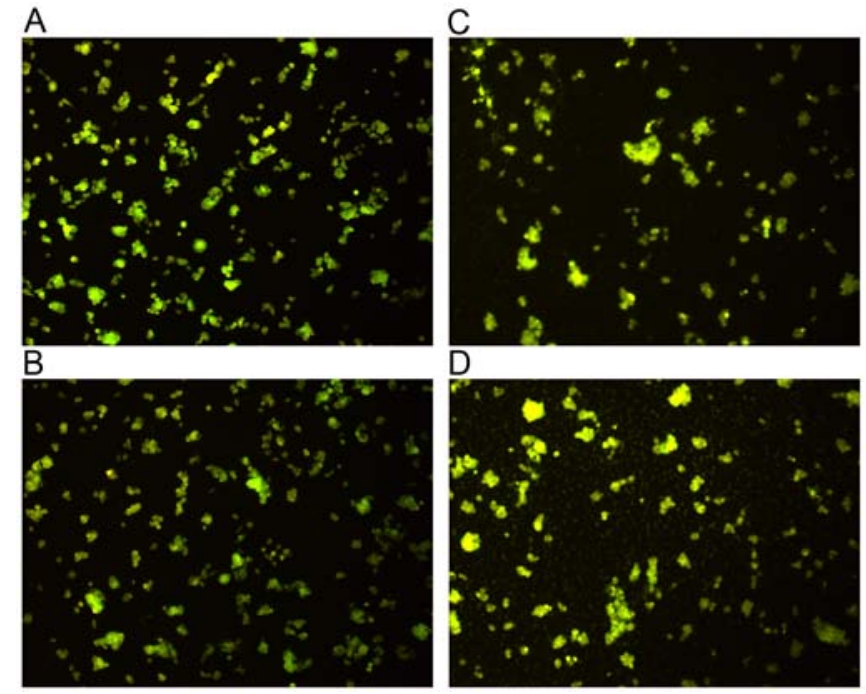

Figure 6. Effect of rapamycin (R) $10 \mathrm{nM}$ (B), fructose-1,6-bisphosphate (FBP) $10 \mathrm{mM}(\mathrm{C})$ and rapamycin (R) + fructose-1,6-bisphosphate (FBP) $10 \mathrm{mM}$ (D) on the autophagy of HepG2 cells compared with the control group (A). Images were obtained by a fluorescent inverted microscope.

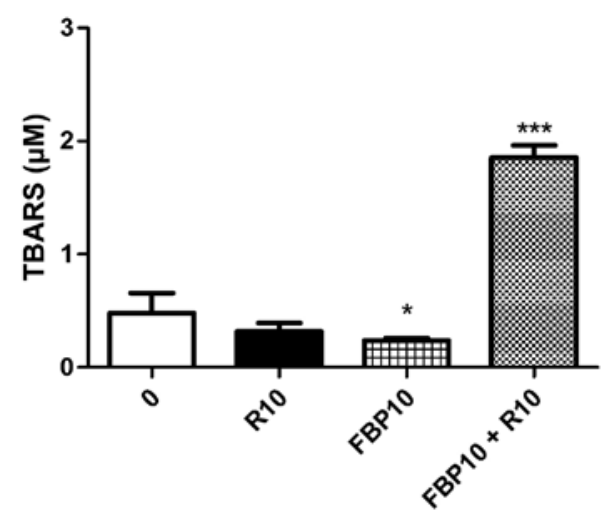

Figure 7. Effect of FBP on oxidative stress measured by TBARS. Data represent the mean $\pm \mathrm{SD}\left({ }^{*} \mathrm{P}<0.05\right.$ and ${ }^{* * * *} \mathrm{P}<0.001$ vs. control $)$.

combination (Fig. 5E) and a significantly increased senescent nuclei in the R and FBP isolated, when compared to control group.

Autophagy, another cellular death mechanism that involves cell degradation of unnecessary or dysfunctional components (25), was analyzed in HepG2 cells through the use of acridine orange dye. No significant differences were fund between the study groups (Fig. 6).

The oxidative stress can provoke cellular damage. For this reason, we analyzed thiobarbituric acid reactive substances (TBARS) (26). Our results showed an antioxidant effect of FBP, but in association with $\mathrm{R}$, it provokes a significant increase in the release of free radicals in relation to the other groups (Fig. 7).

\section{Discussion}

HCC is closely linked with chronic inflammation. This association involves the time factor: the longer the inflammation persists, the greater the risk of developing cancer (27). 
Rapamycin, a known immunosuppressant used in kidney transplant patients, also acts by inhibiting the complex of the mammalian target of rapamycin, mTOR. Also known as FKBP12-rapamycin associated protein (FRAP), mTOR is a serine/threonine protein kinase that promotes cell proliferation and differentiation (28). Therefore, rapamycin is currently being used to treat certain types of cancer (29). However, its use is limited due to its toxicity and resistance to prolonged use, which causes adverse events, mainly nephrotoxicity (30). For this reason, the association with other substances in order to avoid adverse events becomes essential. The FBP, a sugar belonging to glycolytic cellular route that has some therapeutic effects in inflammatory diseases, such as rheumatoid arthritis and septicemia (31), was chosen for the combination with rapamycin.

Our first results showed that rapamycin and FBP singly decreases the proliferation of HepG2 cells. However, when used in combination, rapamycin was effective at lower doses, suggesting a decrease in the therapeutic dosage. In essence, rapamycin has a high degree of toxicity and when associated with FBP showed an antiproliferative effect, which indicated that the association could result in greater effectiveness of rapamycin at concentrations that do not significantly decrease proliferation. Despite the combination decrease the efficiency of FBP, increased the efficiency of $10 \mathrm{nM}$ rapamycin, which was our target. This effect may have been caused by necrosis (cytotoxicity), apoptosis, autophagy or senescence. Therefore, with the intention of proving that this association has no cytotoxicity, we measured LDH that did not demonstrate correlation between the ceasing of cell proliferation and death due to necrosis, showing that the combination of the substances does not cause cellular toxicity.

Inflammatory mediators, such as cytokines, free radicals, prostaglandins, and growth factors can induce changes in cellular homeostasis, leading to the development and progression of cancer. Several inflammatory mechanisms are involved in cancer. One of the most important is the genomic instability caused by inflammation. The activation of leukocytes, especially macrophages and granulocytes, leads to the synthesis of reactive oxygen species (ROS) and nitrogen (RNS) that can cause damage to DNA, proteins and lipids, which may cause mutations in the cells. The free radical damage can be caused by a proinflammatory enzyme, cyclooxygenase- 2 (COX-2), which leads to production of high levels of peroxides within the cells. Therefore, therapies that reduce inflammation prior to immunization can increase the efficacy of immunotherapy $(32,33)$.

In the last two decades, evidence emerged that the molecular level of most chronic diseases, including cancer, are caused by a dysregulated inflammatory response. The tumor necrosis factor $\alpha(\mathrm{TNF}-\alpha)$ exerts regulatory role, by stimulating the biosynthesis of growth factors. It is directly cytotoxic to endothelial cells and can induce the biosynthesis of collagenases, proteases, reactive oxygen intermediates and arachidonic acid metabolites. On the other hand, antiinflammatory interleukins like interleukin-10 (IL-10) have multifaceted properties; such properties include the inhibition of prototypic inflammatory transcription factor nuclear factor kappa B, leading to suppressed cytokine production, reduc- tion of tissue factor expression, and inhibition of apoptosis of macrophages and monocytes after infection (34).

To check if the decrease of cellular proliferation is occurring by the inflammatory route, we analyzed pro-inflammatory cytokines TNF- $\alpha$ and anti-inflammatory IL-10, besides the ratio between them. None of the parameters show changes in relation to the control, and the ratio demonstrated the inflammatory balance between cytokines.

Apoptosis, a programmed cell death, is decreased in cancer cells. Many therapies try to increase apoptosis of these in order to reduce their proliferation.

Another way of cell death that is also reduced in cancer is senescence. Senescence is the aging of the cell that occurs when they stop dividing to replace other cells that, for some reason, failed to metabolize. On the other hand, cancer cells have an enzyme called telomerase that regenerates telomeres of the cell, allowing it to multiply indefinitely (35).

Through the use of fluorescent staining DAPI and the quantification of the images generated by fluorescent microscope, we noted a significant increase of the apoptosis in the association of rapamycin and FBP doses and this test result can be correlated with the percentage of the antiproliferative effect found in the viability assay. Also, there was a significant increase in senescence of nuclei in the isolated rapamycin and FBP compared to the control group. By comparing the results of cell proliferation of the isolated drugs it is safe to conclude that, in spite of being a potential anticancer factor, senescence did not seem to influence the decrease of cell proliferation.

Autophagy, a mechanism that may protect against cancer by isolating damaged organelles, allowing cell differentiation, increasing and promoting cell death of cancerous cells (25), may be related to senescence or apoptosis, because while autophagy decreases, apoptosis and/or senescence increases (36).

When the tumor is established and autophagy is functional it can help the tumor to survive and grow, in the beginning, autophagy can phagocytize the mutated cells and suppresses the tumor. In contrast, apoptosis and senescence processes are irreversible. As no difference was observed between the treatment and control in acridine orange staining analyzes, and we had the result of apoptosis in combination, we did not continue with more specific tests.

The cytoperoxidation is a cell membrane damage caused by free radicals. This toxic effect can be assessed by the formation of thiobarbituric acid reactive substances (TBARS), especially malondialdehyde (MDA) (26). Our results showed that, while FBP singly decreases the cytoperoxidation, the combination of the two drugs cause a significant injury provoked by free radicals, suggesting that this phenomenon might be the cause of cell death by apoptosis.

Apoptosis and senescence, the main routes that limit the growth of tumors, occurs in response to DNA damage or stress. The decision between life and death can be determined by the extent of damage or the duration of stress (37). Based on this, it is observed that due to the increased oxidative stress (TBARS) in cells treated with the combination, they are induced to apoptosis, while cells treated with isolated $\mathrm{R}$ or $\mathrm{F}$ has no increased oxidative stress and become senescent.

The present study promotes for the first time the combination of these two drugs and addresses the importance of trying 
the combination of substances such as FBP with other drugs commonly used to treat cancer, such as rapamycin, for a more effective result and the promotion of life quality for patients in treatment.

In conclusion, our results show that the two drugs individually cause decreased cell proliferation by senescence, however, when combined, increase cell death by apoptosis. These results are very important, since the decrease in apoptosis is one of the main factors that leads the cell to proliferate uncontrollably.

Based on this we can conclude that the concomitant use of rapamycin and FBP could be a promising treatment for patients with hepatocellular carcinoma, because the combination of rapamycin with FBP significantly reduces cell proliferation and, most importantly, brings to reality the possibility of achieving the goal of making an effective subtherapeutic dose, minimizing the serious known reactions to drugs used in cancer therapy today by the increase of free radicals and apoptosis when the association is used.

\section{References}

1. Organization WHO: The top 10 causes of death. Journal 2014.

2. Gonzalez SA: Novel biomarkers for hepatocellular carcinoma surveillance: Has the future arrived? Hepatobiliary Surg Nutr 3: 410-414, 2014.

3. Baird A, Lee J, Podvin S, Kurabi A, Dang X, Coimbra R, Costantini T, Bansal V and Eliceiri BP: Esophageal cancerrelated gene 4 at the interface of injury, inflammation, infection, and malignancy. Gastrointest Cancer 2014: 131-142, 2014.

4. Capece D, Fischietti M, Verzella D, Gaggiano A, Cicciarelli G, Tessitore A, Zazzeroni F and Alesse E: The inflammatory microenvironment in hepatocellular carcinoma: A pivotal role for tumor-associated macrophages. BioMed Res Int 2013: 187204 2013.

5. Bharadwaj S and Gohel TD: Perspectives of physicians regarding screening patients at risk of hepatocellular carcinoma. Gastroenterol Rep (Oxf) gou089, 2015.

6. Salhab M and Canelo R: An overview of evidence-based management of hepatocellular carcinoma: A meta-analysis. J Cancer Res Ther 7: 463-475, 2011.

7. Almeida JRCd: Farmacêuticos em Oncologia: uma nova realidade. Atheneu, Aracaju, p358, 2004 (In Portuguese).

8. Wang Z, Zhou J, Fan J, Qiu SJ, Yu Y, Huang XW and Tang ZY: Effect of rapamycin alone and in combination with sorafenib in an orthotopic model of human hepatocellular carcinoma. Clin Cancer Res 14: 5124-5130, 2008.

9. Wang Z, Zhou J, Fan J, Tan CJ, Qiu SJ, Yu Y, Huang XW and Tang ZY: Sirolimus inhibits the growth and metastatic progression of hepatocellular carcinoma. J Cancer Res Clin Oncol 135 715-722, 2009

10. Wang C, Gao D, Guo K, Kang X, Jiang K, Sun C, Li Y, Sun L, Shu H, Jin G, et al: Novel synergistic antitumor effects of rapamycin with bortezomib on hepatocellular carcinoma cells and orthotopic tumor model. BMC Cancer 12: 166, 2012.

11. Wang Y, Speeg KV, Washburn WK and Halff G: Sirolimus plus sorafenib in treating HCC recurrence after liver transplantation: A case report. World J Gastroenterol 16: 5518-5522, 2010.

12. Wang J: 203985 Everolimus Clinpharm BPCA. 2012. http:// www.fda.gov/downloads/drugs/developmentapprovalprocess/de velopmentresources/ucm320466.pdf. Accessed February 11, 2016

13. Zirkelbach JF: 22088 Temsirolimus Clinpharm BPCA. 2011 http://www.fda.gov/downloads/drugs/developmentapprovalprocess/developmentresources/ucm307049.pdf. Accessed February 11, 2016.

14. Porta C, Paglino C and Mosca A: Targeting PI3K/Akt/mTOR Signaling in Cancer. Front Oncol 4: 64, 2014.

15. Sahin F, Kannangai R, Adegbola O, Wang J, Su G and Torbenson M: mTOR and P70 S6 kinase expression in primary liver neoplasms. Clin Cancer Res 10: 8421-8425, 2004.

16. Cuconati A, Mills C, Goddard C, Zhang X, Yu W, Guo H, Xu X and Block TM: Suppression of AKT anti-apoptotic signaling by a novel drug candidate results in growth arrest and apoptosis of hepatocellular carcinoma cells. PLoS One 8: e54595, 2013.
17. Cendales L, Bray R, Gebel H, Brewster L, Elbein R, Farthing D, Song M, Parker D, Stillman A, Pearson T, et al: Tacrolimus to belatacept conversion following hand transplantation: A case report. Am J Transplant 15: 2250-2255, 2015.

18. Seok SM, Park TY, Park HS, Baik EJ and Lee SH: Fructose-1,6bisphosphate suppresses lipopolysaccharide-induced expression of ICAM-1 through modulation of toll-like receptor-4 signaling in brain endothelial cells. Int Immunopharmacol 26: 203-211, 2015.

19. Zhang JF, Liu JJ, Lu MQ, Cai CJ, Yang Y, Li H, Xu C and Chen GH: Rapamycin inhibits cell growth by induction of apoptosis on hepatocellular carcinoma cells in vitro. Transpl Immunol 17: 162-168, 2007.

20. Dai ZJ, Gao J, Ma XB, Kang HF, Wang BF, Lu WF, Lin S, Wang XJ and Wu WY: Antitumor effects of rapamycin in pancreatic cancer cells by inducing apoptosis and autophagy. Int J Mol Sci 14: 273-285, 2012.

21. Philipp AB, Nagel D, Stieber P, Lamerz R, Thalhammer I, Herbst A and Kolligs FT: Circulating cell-free methylated DNA and lactate dehydrogenase release in colorectal cancer. BMC Cancer 14: 245, 2014.

22. Human Inflammatory Cytokines Kit Instruction Manual. Journal 2008. http://www.bdbiosciences.com/documents/CBA Human Inf_Cytokine_manual.pdf. Accessed February 11, $201 \overline{6}$.

23. Kim TM, Shin SK, Kim TW, Youm SY, Kim DJ and Ahn B: Elm tree bark extract inhibits HepG2 hepatic cancer cell growth via pro-apoptotic activity. J Vet Sci 13: 7-13, 2012.

24. Chiela ECF: Protocol for measuring autophagy. Journal. http:// www.ufrgs.br/labsinal/autofagia.htm. Accessed February 11, 2016.

25. Nepal S and Park PH: Regulatory role of autophagy in globular adiponectin-induced apoptosis in cancer cells. Biomol Ther (Seoul) 22: 384-389, 2014

26. Carlos SP, Dias AS, Forgiarini Júnior LA, Patricio PD, Graciano T, Nesi RT, Valença S, Chiappa AM, Cipriano Jr G, Souza CT, et al: Oxidative damage induced by cigarette smoke exposure in mice: impact on lung tissue and diaphragm muscle. J Bras Pneumol 40: 411-420, 2014.

27. Rutkowski MR and Conejo-Garcia JR: Size does not matter: Commensal microorganisms forge tumor-promoting inflammation and anti-tumor immunity. Oncoscience 2: 239-246, 2015.

28. Asnaghi L, Bruno P, Priulla M and Nicolin A: mTOR: A protein kinase switching between life and death. Pharmacol Res 50: 545-549, 2004

29. McGranahan N, Favero F, de Bruin EC, Birkbak NJ, Szallasi Z and Swanton C: Clonal status of actionable driver events and the timing of mutational processes in cancer evolution. Sci Transl Med 7: 283ra54, 2015.

30. Fervenza FC, Fitzpatrick PM, Mertz J, Erickson SB, Liggett S, Popham S, Wochos DN, Synhavsky A, Hippler S, Larson TS, et al; Mayo Nephrology Collaborative Committee: Acute rapamycin nephrotoxicity in native kidneys of patients with chronic glomerulopathies. Nephrol Dial Transplant 19: 1288-1292, 2004.

31. Azambuja AA, Lunardelli A, Nunes FB, Gaspareto PB, Donadio MV, Poli de Figueiredo CE and de Oliveira JR: Effect of fructose-1,6-bisphosphate on the nephrotoxicity induced by cisplatin in rats. Inflammation 34: 67-71, 2011.

32. Seelaender M, Neto JC, Pimentel GD, Goldszmid RS and Lira FS: Inflammation in the disease: Mechanism and therapies 2014. Mediators Inflamm 2015: 169852, 2015

33. Raza H, John A and Benedict S: Acetylsalicylic acid-induced oxidative stress, cell cycle arrest, apoptosis and mitochondrial dysfunction in human hepatoma HepG2 cells. Eur J Pharmacol 668: $15-24,2011$

34. Goswami B, Rajappa M, Mallika V, Shukla DK and Kumar S: TNF-alpha/IL-10 ratio and C-reactive protein as markers of the inflammatory response in CAD-prone North Indian patients with acute myocardial infarction. Clin Chim Acta 408: 14-18, 2009.

35. Raouf S, Weston C and Yucel N; Reproducibility Project: Cancer Biology: Registered report: senescence surveillance of premalignant hepatocytes limits liver cancer development. Elife: Jan 26, 2015. doi: 10.7554/eLife.04105.

36. Vessoni AT,Filippi-Chiela EC,Menck CF and Lenz G: Autophagy and genomic integrity. Cell Death Differ 20: 1444-1454, 2013.

37. Suzuki K and Matsubara H: Recent advances in $p 53$ research and cancer treatment. J Biomed Biotechnol 2011: 978312, 2011. 